\title{
El síndrome de alienación parental: una forma de maltrato infantil.
}

\author{
The parental alienation syndrome: a way of mistreatment \\ on children.
}

\section{Segura 1 , MJ. Gil² y MA. Sepúlveda ${ }^{3}$}

\section{RESUMEN}

El modelo tradicional de familia ha sufrido grandes cambios en los últimos años existiendo en las últimas décadas un gran incremento de separaciones y divorcios. Es importante garantizar el derecho fundamental de los/as menores a relacionarse adecuadamente tanto con su padre como con su madre manteniendo todos sus vínculos. Sin embargo, hay situaciones en las que existen obstaculizaciones por parte de uno de los progenitores a las relaciones de sus hijos e hijas con el otro progenitor que desembocan en el Síndrome de Alienación Parental, una de las formas mas sutiles de maltrato infantil, casi desconocida hasta ahora, pero que está cobrando vigencia día a día y que produce un grave daño en el bienestar emocional y en el desarrollo de los menores que lo sufren.

En este trabajo se estudia el Síndrome de Alienación Parental como forma de maltrato infantil y se exponen algunas de las conductas maltratantes por parte de las personas que lo ejercen. Finalmente, se presentan dos casos extraídos de la práctica del Servicio Punto de Encuentro Familiar de Sevilla, donde se detecta la existencia de este síndrome, y se analizan las consecuencias psicopatológicas que estas situaciones desarrollan en la infancia así como las vías de intervención.

Palabras clave: Divorcio, Punto de Encuentro Familiar, Síndrome de Alienación Parental, Maltrato Infantil.

\section{ABSTRACT}

The traditional model of family has suffered in the last years important changes and a great increase of splitting and divorces have been produced. It's important to guarantee the fundamental right of children to be related adequately with both parents, mother and father, keeping on all their affective attachments. However, sometimes one of the progenitors hinders the relationship among the other one with their children, and it leads to the Parental Alienation Syndrome, one of the most subtle ways of mistreatment in children, almost unknown up to now, although it is getting transcendence since it produces an important damage in the emotional welfare and the development of children affected.

Parental Alienation Syndrome is presented in this paper as a way of children abuse and some kind of mistreating behaviours, psychopathological consequences on childhood and the ways to intervene are exposed. Two cases taken from our experience in the Familiar Meeting Point Service of Seville, where the existence of this syndrome has been detected, as well as the ways of intervention are also presented.

Key words: Divorce, Familiar Meeting Point, Parental Alienation Syndrome, Children Mistreatment.

Correspondencia: $M^{a}$ Ángeles Sepúlveda García de la Torre. Punto de Encuentro Familiar de Sevilla. c/ San Víctor n 5 , local, 41005 Sevilla, Telf.: 954653557; Fax: 954653574; E- mail: pdefsevilla@amuvi.info.

1 Licenciada en Psicología. Experta Universitaria en Criminología y en Mediación y Orientación Familiar. Coordinadora de Punto de Encuentro Familiar de Sevilla.

2 Licenciada en Psicología. Experta Universitaria en Mediación y Orientación Familiar. Psicóloga de Punto de Encuentro Familiar de Sevilla.

3 Especialista en Medicina Legal y Forense. Experta en Mediación y Orientación Familiar. Supervisora del Programa Punto de Encuentro Familiar de Sevilla. 


\section{INTRODUCCIÓN:}

La infancia es la etapa más bella de la evolución hacia la madurez, en la que existe una gran vulnerabilidad que debe ser protegida. Se considera que la familia es la primera fuerza (en el tiempo y por su trascendencia) que interviene modulando las experiencias infantiles determinando conductas y participando en la personalidad progresiva [I], es en ella donde nos tenemos que centrar para dar explicación a las conductas y comportamientos de nuestros menores.

El modelo tradicional de familia en los últimos años ha sufrido grandes cambios, tanto en sus estructuras como en sus interacciones, existiendo en las últimas décadas un enorme incremento de separaciones y divorcios, que hacen necesaria la creación de instrumentos procesales por parte del ordenamiento jurídico. Así, la legislación ha tenido que ir adaptándose a las nuevas realidades familiares y ha tenido que regular las relaciones entre los hijos de padres y madres separados. A través del articulo 94 del Código Civil Español se establece que "el progenitor que no tenga consigo a los hijos menores o incapacitados gozará del derecho de visitarlos, comunicar con ellos y tenerlos en su compañía; el Juez determinará el tiempo, modo y lugar del ejercicio de este derecho, que podrá limitar o suspender si se dieren graves circunstancias que así lo aconsejen o se incumplieren grave y reiteradamente los deberes impuestos por resolución judicial".

Sea cual fuere el miembro de la pareja (madre o padre) con quien conviva el niño se ha de garantizar la relación con ambos tras la separación; los regímenes de visitas tienen varias e importantes funciones psicológicas para el desarrollo de la infancia [2]; las visitas protegen los derechos del menor de acceso al progenitor no custodio, al igual que los de este último; así mismo, se protege el vínculo emocional entre el niño y sus progenitores, ya que se le proporcionan modelos de rol alternativos $y$, por último, se permite al progenitor custodio que descanse de su responsabilidad en la crianza.

El problema surge no por el hecho de que los padres, responsablemente, decidan poner fin a su vida en común, sino cuando se hacen partícipes a sus hijos e hijas de los conflictos que ha generado la separación. Entonces los niños se ven inmersos en los problemas de los adultos, tomando partido en el conflicto, pasando a formar parte de los bloques enfrentados, y reproduciendo las disputas de los mayores. En estos casos, la opinión de los menores estará mediatizada, en mayor o menor grado, por el problema en el que están inmersos y por las presiones que están recibiendo. En determinados casos, es fácil apreciar como el niño adquiere un papel protector del progenitor al que siente como más débil, "el perdedor o el abandonado", ejerciendo una función defensora que no le corresponde. Esta función puede llevarle incluso a rechazar cualquier contacto con el otro progenitor, justificando su postura ante todas las instancias que le pide explicaciones, incluido el Juez. Por otra parte, los menores envueltos en una situación de ruptura familiar conflictiva sufren una aguda sensación de shock, de miedo intenso, teñido todo ello por un sentimiento de profunda confusión [3], con consecuencias negativas a nivel psicoemocional y conductual $[4,5,6]$. Estos menores presentan, con frecuencia, sentimientos de abandono y culpabilidad, rechazo, impotencia e indefensión, inseguridad, así como estados de ansiedad y depresión y conductas regresivas, disruptivas y problemas escolares [7].

Esta sintomatología puede verse incrementada al ser presionado para participar en actos legales derivados del conflicto de separación, pasando a formar parte de la propia disputa en la medida en que sus sentimientos son utilizados como argumentos o armas arrojadizas. Los padres pueden tomar al pie de la letra esta negativa expresada y utilizarla para descalificarse mutuamente, e incluso pueden decidir llevar a su hijo delante del Juez para que este también pueda escucharle y valorar si es influencia de uno o, por el contrario, la ineficacia del otro, lo que motiva dicha actitud. 
La persistencia del conflicto, especialmente cuando las disputas se pretenden resolver judicialmente, produce un agotamiento mental de quien se encuentra inmerso en él, disminuyendo la capacidad atencional para responder de manera efectiva y adaptada a las demandas propias y del entorno, repercutiendo negativamente en la capacidad de detectar y satisfacer las necesidades de sus hijos, especialmente las emocionales. Sin duda alguna los procedimientos contenciosos generan un estrés en los progenitores y en los hijos e hijas que repercuten negativamente en el equilibrio emocional de todos ellos, y que llega a ser de tal magnitud que las necesidades infantiles quedan relegadas a un segundo plano, pudiendo llegar a constituir un factor de riesgo de enfermedad mental en la infancia.

Por hacernos una idea de la magnitud del problema, en España en los años 2003 y 2004 hubo I 88.824 y 205.520 Procesos de Familia de los cuales 53.895 en 2003 y 58.542 en el año 2004 fueron de tipo contencioso [8].

Dentro de los conflictos más frecuentes que surgen, y a veces de más difícil solución judicial, son los relacionados con el cumplimiento del régimen de visitas. En este contexto surge como solución alternativa el Programa Punto de Encuentro Familiar, como un lugar neutral, destinado a facilitar el cumplimiento de las medidas acordadas por los Juzgados de Familia y otras instituciones como la Administración Autonómica, respecto al ejercicio del derecho de visita o relación entre el/la menor y sus familiares, dotados de profesionales que actúan interviniendo sobre las familias desde distintas esferas psicosociales. En el Punto de Encuentro se realizan las visitas de los casos derivados judicialmente y a su vez se ejecuta un programa de orientación e intervención familiar individualizado, adecuado a la problemática de cada caso.

El problema más importante y frecuente detectado en los Puntos de Encuentro, tanto de España y resto de Europa como de Estados Unidos y Canadá, por la frecuencia que se produce y por sus graves consecuencias para la necesaria relación del niño con el progenitor sin la custodia, es el de las interferencias en las visitas por parte del progenitor que tiene la custodia [9], si bien, como señala Turkat [10], antes de discutir los tipos específicos de interferencia, conviene aclarar lo que sería una conducta de "no interferencia". En este caso el niño no siente la pérdida de ninguno de sus padres, ya que el progenitor con el que convive anima al hijo y al padre a que se relacionen con frecuencia y se involucren mutuamente en sus vidas. La situación de no interferencia suele acompañar a un régimen de custodia que funcionalmente conlleva la toma de decisiones conjunta de los padres a favor de los hijos. Los niños suelen visitar con frecuencia al padre, lo llaman por teléfono cuando quieren o lo necesitan y disfrutan de los beneficios de la implicación de los padres en el colegio, en actividades extraescolares y de cualquier otro tipo.

La interferencia sería el caso contrario que comienza con una obstaculización leve de la relación del hijo o hija con el progenitor no custodio y puede llegar a ser de tal tipo que nos encontramos ante una verdadera obstaculización a la relación del/la menor con el progenitor no custodio de tal magnitud que constituye un tipo de maltrato infantil cuyas estrategias sutiles, su apoyo en creencias socialmente aceptadas y su desarrollo en la intimidad del hogar hacen difícil su descubrimiento y abordaje. Estos niños, de adultos, tienen una gran probabilidad de ser inválidos emocionales e intelectualmente rígidos [ I I].

\section{EL SINDROME DE ALIENACIÓN PARENTAL:}

La primera definición que se realiza sobre esta realidad, es de Richard Gardner [12] en 1985, que define el Síndrome de Alienación Parental (S.A.P.) como un desorden que surge principalmente en el contexto de las disputas por la guarda y custodia de los niños. Su primera manifestación 
es una campaña de difamación contra uno de los padres por parte del hijo, campaña que no tiene justificación. El fenómeno resulta de la combinación del sistemático adoctrinamiento (lavado de cerebro) de uno de los padres y de la propia contribución del hijo a la denigración del padre rechazado.

Otros autores como Aguilar lo definen como un trastorno caracterizado por un conjunto de síntomas que resultan del proceso por el cual un progenitor transforma la conciencia de sus hijos, mediante distintas estrategias, con objeto de impedir, obstaculizar o destruir sus vínculos con el otro progenitor [I I]. Los comportamientos y estrategias que el progenitor alienante pone en juego suelen ser sutiles, en la tabla I se resumen algunos de los más frecuentemente encontrados [13].

TABLA I: Comportamientos y estrategias obstaculizadoras del progenitor alienante. Adaptado de [13].

- Rehusar pasar las llamadas telefónicas a los hijos.

- Organizar varias actividades con los hijos durante el período que el otro progenitor debe normalmente ejercer su derecho de visita.

- Presentar al nuevo cónyuge a los hijos como su nueva madre o su nuevo padre.

- Interceptar el correo y los paquetes mandados a los hijos.

- Desvalorizar e insultar al otro progenitor delante de los hijos.

- Rehusar informar al otro progenitor a propósito de las actividades en las cuales están implicados los hijos (partidos deportivos, actuaciones teatrales, actividades escolares...)

- Hablar de manera descortés del nuevo cónyuge del otro progenitor.

- Impedir al otro progenitor el ejercer su derecho de visita.

- "Olvidarse" de avisar al otro progenitor de citas importantes (dentista, médico, psicólogo...)

- Implicar a su entorno (su madre, su nuevo cónyuge...) en el lavado de cerebro de los hijos.

- Tomar decisiones importantes a propósito de los hijos sin consultar al otro progenitor (elección de la religión, elección de la escuela).

- Cambiar (o intentar cambiar) sus apellidos o sus nombres.

- Impedir al otro progenitor el acceso a los expedientes escolares y médicos de los hijos.

- Irse de vacaciones sin los hijos y dejarlos con otra persona, aunque el otro progenitor esté disponible y voluntario para ocuparse de ellos.

- Contar a los hijos que la ropa, que el otro progenitor les ha comprado, es fea, y prohibirles ponérsela.

- Amenazar con castigo a los hijos si se atreven a llamar, a escribir o a contactar con el otro progenitor de la manera que sea.

- Reprochar al otro progenitor el mal comportamiento de los hijos. 
Si bien es cierto que para realizar una campaña de desacreditación respecto al progenitor alienado, el alienador debe ser consciente de los actos que realiza, también es cierto que a menudo, este no es plenamente consciente de que está produciendo un daño psicológico y emocional en sus hijos/as, y de las consecuencias que ello va a tener a corto y largo plazo en el o la menor. Bolaños entiende el SAP como un síndrome familiar en el que cada uno de sus participantes tiene una responsabilidad relacional en su construcción y por tanto en su transformación; teniendo en cuenta que el elemento principal es el rechazo más o menos intenso de los hijos hacia uno de los cónyuges, propone modificar la nomenclatura clásica de Gardner por la de Progenitor Aceptado y Progenitor Rechazado [14].

Cuando el SAP entra en contacto con el sistema legal se convierte en un Síndrome Jurídico Familiar [I5], en el que los abogados, jueces, peritos y otros profesionales vinculados adquieren responsabilidad en su continuidad. La negativa de los hijos adquiere auténtica trascendencia cuando se expresa en un juzgado, ya que se desencadenan entonces acusaciones, búsquedas de explicaciones y acciones encaminadas a resolver el problema que hace que la instancia judicial se convierta en parte para resolver el mismo [16], de tal manera que debamos incluirla como un elemento de vital importancia de los componentes del Síndrome. El sistema judicial, con la intervención de los letrados, por el privilegiado lugar que ocupan tanto para mantener como agravar el SAP podría incluirse dentro del maltrato institucional [9].

Es posible identificar diferentes niveles de intensidad en el rechazo que muestran los niños y niñas afectados por el SAP: rechazo leve, moderado e intenso [1 4]:

- El rechazo leve se caracteriza por la expresión de algunos signos de desagrado en la relación con el padre o la madre. No hay evitación y la relación no se interrumpe.

- El rechazo moderado se caracteriza por la expresión de un deseo de no ver al padre o la madre acompañado de una búsqueda de aspectos negativos del progenitor rechazado que justifique su deseo. Niega todo afecto hacia él y evita su presencia. El rechazo se generaliza a su entorno familiar y social. La relación se mantiene por obligación o se interrumpe.

- El rechazo intenso supone un afianzamiento cognitivo de los argumentos que lo sustentan. El niño se los cree y muestra ansiedad intensa en presencia del progenitor rechazado. El rechazo adquiere características fóbicas con fuertes mecanismos de evitación. Puede aparecer sintomatología psicosomática asociada.

El rechazo puede aparecer inmediatamente después de la ruptura o en periodos posteriores que pueden alcanzar varios años después, generalmente asociados a momentos concretos del nuevo ciclo evolutivo familiar. De esta manera se distinguen, siguiendo a diferentes autores, dos tipos de rechazo en función del momento en que aparecen: primario y secundario, que configuran una dinámica relacional.

\section{DINÁMICA RELACIONAL DEL RECHAZO:}

Tras el proceso de separación puede aparecer un rechazo de los hijos/as en común hacia uno de los progenitores. El rechazo puede ser primario o secundario, el primero como reacción inmediata a la ruptura de pareja y el secundario aparece en separaciones más lentamente gestadas. La existencia del rechazo a uno de los progenitores va a suponer la aparición de conflictos en el desarrollo del régimen de visitas. Ante esta situación, uno de los dos progenitores, normalmente el rechazado, pone en conocimiento del órgano judicial la situación lo que producirá un aumento del rechazo del/la menor. Tras esta situación aparecerán múltiples problemas en las relaciones paterno 
y materno filiales con el progenitor no aceptado. Finalmente tendrá como consecuencia directa la desaparición de las relaciones filiales por la negativa de los/as menores (Fig. I).

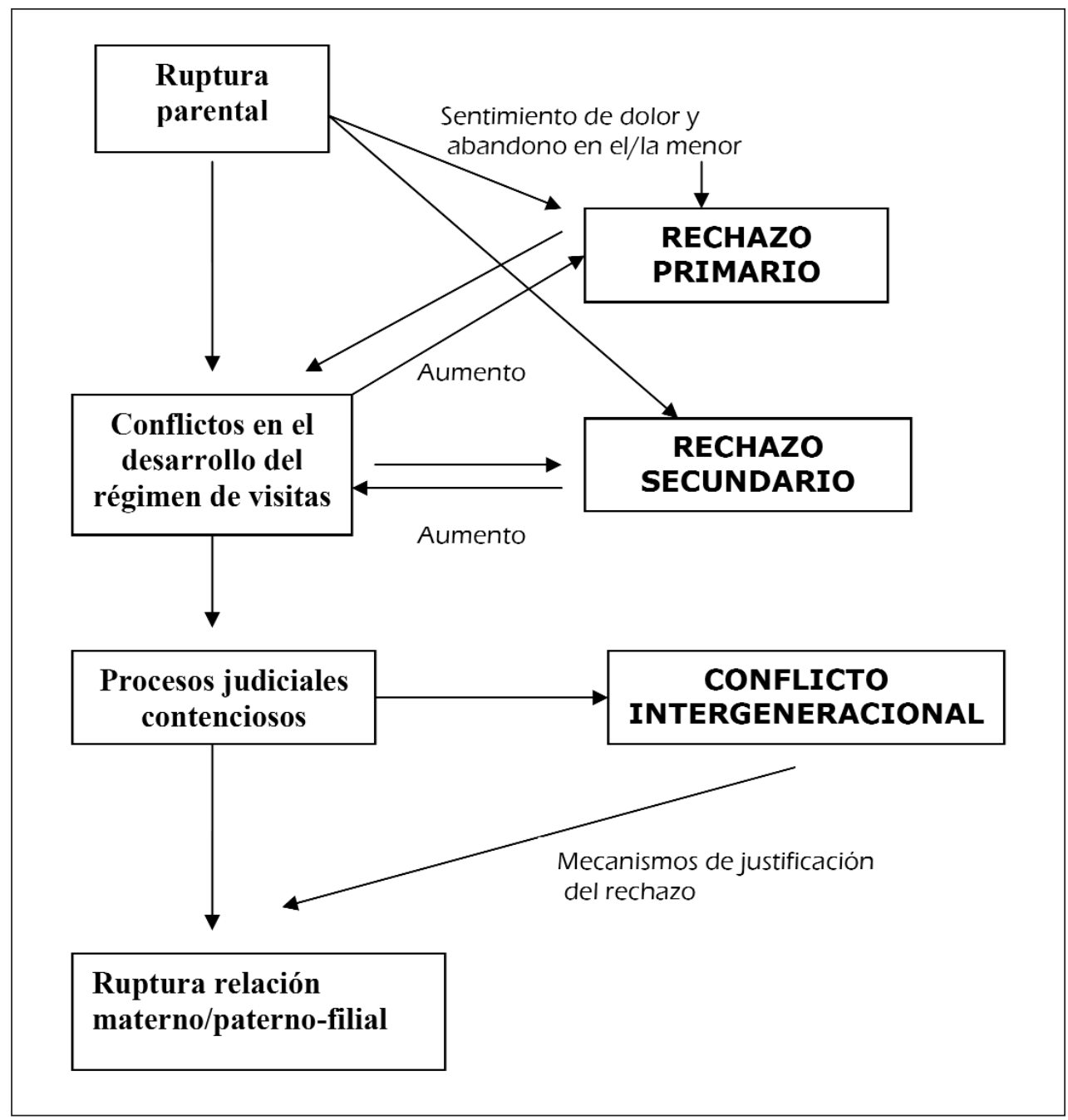

Figura 1. Dinámica relacional del rechazo.

Tal como queda recogido por diferentes autores $[14,15,16]$, se pueden distinguir dos dinámicas relacionales en función del tipo de rechazo.

\section{Dinámica relacional del rechazo primario.}

Aparece en los momentos inmediatos a la separación. Es propio de rupturas bruscas e impulsivas, en las que se dan los siguientes factores:

- El progenitor rechazado (habitualmente el padre) abandona el hogar de forma inesperada o tras haber iniciado una relación afectiva extramatrimonial.

- Los hijos no reciben una explicación conjunta por parte de sus progenitores acerca de lo que está ocurriendo. 
- Descubren que el progenitor rechazado se ha ido a través del progenitor aceptado (habitualmente la madre), quien no puede ocultar los sentimientos que ello le produce.

- El progenitor rechazado intenta que sus hijos se adapten de forma inmediata a su nueva realidad.

- Los hijos presentan resistencias para ello, pues su deseo es contrario a la ruptura.

- El progenitor rechazado culpabiliza al progenitor aceptado porque los niños no quieren verle y le exhorta para que los obligue.

- El progenitor aceptado se siente identificado con sus hijos. No puede obligarles.

- El progenitor rechazado pone la cuestión en manos del juzgado y pide al juez que se obligue al progenitor aceptado para que pueda ver a sus hijos.

- Hay descalificaciones durante el proceso legal que acrecientan las dificultades emocionales.

- Los hijos pueden ser llamados al juzgado para expresar los motivos por los que no quieren ver al progenitor rechazado.

- A medida que se ven obligados una y otra vez a negar la figura del progenitor rechazado van encontrando argumentos cognitivos que justifiquen su actitud.

- El rechazo se generaliza a otros familiares del progenitor rechazado: abuelos, tíos, primos.

- Las familias de origen compiten entre sí. Una protege al progenitor aceptado y a los hijos, descalificando la actitud del progenitor rechazado. La otra exige una relación con los hijos e intenta apoyar al progenitor rechazado para conseguirla.

- El rechazo tiende a cronificarse.

\section{Dinámica relacional del rechazo secundario.}

Tras la ruptura, los hijos mantienen relación con el progenitor rechazado hasta que un día deciden romperla.

- Existe un conflicto larvado entre los progenitores, que surge cuando deben negociar algún aspecto nuevo relacionado con sus hijos: un cambio de colegio, unas pautas educativas, un cambio en el régimen de visitas, una modificación de la pensión, etc.

- Los hijos sienten las continuas descalificaciones mutuas que sus progenitores se hacen a través suyo. Al mismo tiempo "juegan" a darles informaciones contradictorias que generan mayor enfrentamiento entre ellos.

- Ambos progenitores describen cómo sus hijos deben "cambiar el chip" después de estar con el otro.

- Las visitas se convierten en algo tensional. El rendimiento escolar puede verse afectado. Pueden aparecer síntomas psicosomáticos.

- Los hijos deciden no volver a ver al progenitor rechazado bajo cualquier excusa: forma de cuidarles, desatención, malos tratos.

- Encuentran apoyo y comprensión en el progenitor aceptado.

- Cualquiera de los dos decide llevar el asunto al juzgado, pidiendo que los hijos hablen con el juez.

- El rechazo tiende a cronificarse. 


\section{CONSECUENCIAS DEL SAP EN MENORES:}

Aunque existen aún pocos estudios acerca de las consecuencias que un SAP va a tener a corto y largo plazo en los/las menores, sí se ha podido observar, en lugares como el Punto de Encuentro Familiar, ante la simple presencia física del progenitor rechazado, reacciones de ansiedad, crisis de angustia y miedo a la separación; el progenitor aceptado informa además de alteraciones a nivel fisiológico en los patrones de alimentación y sueño, conductas regresivas, y de control de esfínteres. La sintomatología observada, coincide con la descrita en la literatura para las diferentes situaciones que atraviesan los/as menores que sufren maltrato emocional, a continuación se exponen los problemas más frecuentemente detectados:

Trastornos de ansiedad: los menores viven el momento de las visitas con un fuerte estrés, en estos casos observamos respiración acelerada, enrojecimiento de la piel, sudoración, elevación del tono de voz, temblores, finalizando en desbordamiento emocional, no pudiendo estar delante del progenitor rechazado con serenidad y normalidad. En ocasiones para afrontar las visitas, acuden a las mismas bajo los síntomas de medicamentos ansiolíticos como Clorazepato Potásico (Tranxilium ${ }^{\circledR}$ Pediátrico).

Trastornos en el sueño y en la alimentación: derivado de la situación anterior, son menores que a menudo manifiestan que sufren pesadillas, así como problemas para conciliar o mantener el sueño. Por otro lado pueden sufrir trastornos alimenticios derivados de la situación que viven y no saben afrontar, ingiriendo alimentos compulsivamente o no alimentándose, hechos que el progenitor alienador suele utilizar para cargar contra el otro, haciendo ver que estos síntomas son debidos al sufrimiento del/la menor por no querer ver al progenitor rechazado por el daño que este les ha producido.

Trastornos de conducta:

- Conductas agresivas: cuando nos encontramos ante un nivel severo, en el que como hemos descrito anteriormente las visitas se hacen imposibles; a menudo se observa en los menores problemas de control de impulsos, teniendo que ser contenidos en ocasiones por los profesionales. Las conductas agresivas pueden ser verbales como insultos, o incluso físicas, teniendo que frenar la situación.

- Conductas de evitación: hay ocasiones en las que los menores despliegan una serie de conductas para evitar enfrentarse a la visita, como pueden ser somatizaciones de tipo ansioso que producen una llamada de atención en el progenitor alienador y que tienen como consecuencia no pasar a la visita.

- Utilizan lenguaje y expresiones de adultos: a menudo nos encontramos con pequeños/as que verbalizan términos judiciales, así como tienen un claro conocimiento acerca de dichos procesos. Por otro lado realizan verbalizaciones que son un claro reflejo de la fuerte conflictividad que viven y de la postura que han tomado en el conflicto, que es al lado incondicional del progenitor no rechazado.

- Dependencia emocional: las/os menores que viven las situaciones que hemos descrito, sienten miedo a ser abandonados por el progenitor con el que conviven, ya que saben, y así lo sienten, que su cariño está condicionado. Tienen que odiar a uno para ser querido y aceptado por el otro, y ese odio tiene que ser sin ambivalencias; todo ello va a crear una fuerte dependencia emocional para el/la menor. Todo ello va a tener como consecuencia la creación de una relación patológica entre progenitor e hijo/a.

- Dificultades en la expresión y comprensión de las emociones: suelen expresar sus emociones de forma errónea, centrándose excesivamente en aspectos negativos. Por otro 
lado muestran falta de capacidad empática, teniendo dificultades para ponerse en el lugar de otras personas, manteniendo una actitud rígida ante los distintos puntos de vista que ofrezca el progenitor rechazado.

- Exploraciones innecesarias: en los casos severos, pueden darse denuncias falsas por maltrato hacia los/as menores, estos se van a ver expuestos a numerosas exploraciones por parte de diversos profesionales, las cuales, además de ser innecesarias, producen una fuerte situación de estrés. También hace que adopten un rol de "víctimas" de algo que no han sufrido pero que debido a la campaña de denigración del progenitor alienado, y a la autonomía de pensamiento, toman como algo real, teniendo unas consecuencias devastadoras para su desarrollo psicológico.

Ante la presencia de la sintomatología descrita, indicar que a nivel de relación paterno/materno filial, es aconsejable que los menores continúen teniendo relación con el progenitor alienado, ya que una de las estrategias que va a utilizar el progenitor alienador va a ser que se suspenda el régimen de visitas utilizando tácticas como las descritas anteriormente. Por ello es importante además dar pautas y orientaciones adecuadas al progenitor alienado para que durante los contactos no favorezca con su conducta o verbalizaciones, el mantenimiento del SAP. Dichas orientaciones van encaminadas a no realizar reproches a los menores, ni entrar en sus ataques, teniendo en cuenta que no hablan por ellos mismos, dar respuestas que satisfagan un reproche o necesidad que transmite el/la menor, en los casos en que estemos ante un nivel leve o moderado en el que se realicen visitas, centrar estas en un ambiente lúdico entre ambos, buscar actividades que sean del agrado del menor, y posteriormente tareas más personales, etc.

\section{EXPERIENCIA EN PUNTO DE ENCUENTRO FAMILIAR DE SEVILLA: CASOS PRÁCTICOS.}

CASO I:

- Persona que ejerce la Guarda y Custodia: la madre.

- Persona que ejerce el régimen de visitas: el padre.

- Número de menores: 3, Marta, Juan y Aurora, 5, 8 y 12 años respectivamente.

- Antecedentes: 8 meses sin realizarse las visitas. Rechazo de los menores a relacionarse con su padre, denuncias por incumplimiento por ambas partes.

- Actitud durante la visita: los menores acuden a Punto de Encuentro Familiar acompañados por su madre, aferrados unos a otros, compungidos, llorando los pequeños. Manifiestan abiertamente no querer ver a su padre, mientras su madre les dice: "qué le vamos a hacer, ya queda menos para que esto se acabe, una hora se pasa pronto". Durante la hora que dura la visita, Juan y Aurora permanecen agarrados a su hermana pequeña, sin permitir siquiera contacto visual entre ella y su padre. El nivel de tensión es elevado, incluso hay que intervenir para que cesen las agresiones verbales y hay conatos de agresión física teniendo que frenar a Juan. El tono de los menores es de reproche y frases como: "cómo quieres que tengamos ganas de verte con el daño que nos has hecho tú y toda tu familia", "nos abandonaste, ahora no te queremos", "no cuidaste de nosotros cuando te necesitábamos", "un día me obligaste a ir al parque y pasé mucho frío","recuerdo que me odiabas cuando estaba en la barriga de mamá" "has denunciado a mamá" "por tu culpa mamá tiene una comparecencia en el juzgado" (dicho por la niña de 5 años), "tu eres un gilipollas". Todo esto lo manifiestan a la vez que se muestran muy nerviosos, frotándose las manos, con sudoración, respiración acelerada y entrecortada etc, manifestando que lo están pasando muy mal por su culpa, que incluso tienen que tomar Tranxilium Pediátrico ${ }^{\circledR}$ para venir a verlo, de lo malos que se ponen, culpando única y exclusivamente a su padre de esto. Su padre intenta aclararles lo sucedido pero los pequeños le 
reprochan, "padre es el que cuida de sus hijos y tú nos abandonaste", "por tu culpa estamos así". El padre pierde los nervios en la visita, poniéndose a gritar delante de sus hijos y diciéndoles que: "eso no puede ser cosa vuestra. Vuestra madre os come el coco. Aurora, piensa por ti misma, no por lo que nadie te diga". Esto no hace más que empeorar la situación, ya que Aurora se pone aún más nerviosa, deambulando por la sala, gritando, insultando a su padre; exigiendo salir de la sala con sus hermanos porque ya ha pasado la hora de visita.

Al llegar su madre los menores la reciben con un angustioso y prolongado abrazo, mientras le cuentan que su padre les ha insultado; su madre, compungida y con rostro de resignación les consuela y acaricia mientras les dice: "ya ha pasado todo, ustedes habéis hecho lo que habéis podido, si él no quiere cambiar es su problema" y se marchan abrazados los unos con los otros, sin apenas poder caminar.

CASO II:

- Persona que ejerce la Guarda y Custodia: el padre.

- Persona que ejerce el régimen de visitas: la madre.

- Número de menores: I, Pablo de 7 años.

- Antecedentes: un año y medio sin relacionarse con su madre. La madre de Pablo tiene nueva pareja, el padre de Pablo también tiene nueva pareja, a la que el menor llama "mamá". El padre ha interpuesto varias denuncias contra la madre por presuntos abusos sexuales a Pablo, que fueron investigados, determinándose la no existencia de los mismos.

- Actitud durante la visita: Pablo acude a Punto de Encuentro Familiar desde hace unos tres meses aproximadamente para realizar las visitas con su madre. Durante las visitas Pablo dice a su madre que no quiere verla, mientras permanece en una esquina de la sala, paralizado, y, con expresión de miedo, dice a su madre: "tu sabes el daño tan grande que me has hecho"; "sí, lo de los abusos y esas cosas" "me acuerdo cuando estaba en tu barriga que te acostabas con otros hombres", "mi mamá solo se acuesta con mi papá". Su madre intenta jugar con él, pero en cuanto se acerca unos metros, sale corriendo, gritando. En otras ocasiones pasa toda la visita sin hablar, jugando en solitario o leyendo una revista, sin contestar a ninguna pregunta que le hace su madre, respecto a cómo le va en el colegio. El padre de Pablo acude a Punto de Encuentro con el rostro serio, manifestando que él "bastante hace con cumplir la orden judicial", "no puede obligar al niño a relacionarse con la madre que es perjudicial para él".

\section{DISCUSIÓN:}

En estos menores se observan diferentes síntomas, entre otros, que hacen pensar que estamos ante una situación de Síndrome de Alienación Parental. A continuación se numeran los Criterios de identificación de un niño alienado [17, |8].

- Presentan un elevado nivel de ansiedad ante la sola presencia física de su padre, observándose desbordamiento emocional rompiendo en llanto, sudoración, agitación, etc. Manifestando incluso la toma de fármacos para acudir a las visitas.

- Su nivel de ansiedad no se corresponde con lo que verbalizan.

- Falta de ambivalencia con respecto al sentimiento de odio hacia su padre. Su sentimiento es inflexible, incuestionable.

- Falta de sentimiento de culpabilidad por la actitud mantenida en la visita con respecto a su padre. contribuye activamente.

- Las razones alegadas para justificar el desacreditar al progenitor objeto son a menudo débiles, frívolas o absurdas. 
- La animadversión hacia el progenitor rechazado carece de la ambivalencia normal en las relaciones humanas.

- El niño afirma que la decisión de rechazar al progenitor objeto es exclusivamente propia.

- El niño apoya reflexivamente al progenitor con cuya causa está alineado.

- Ausencia de culpabilidad.

- Se evidencian escenarios prestados

- Generalización a la familia extensa.

- Los menores cuentan hechos que no han vivido, manifestándolos como propios.

- Buscan pretextos absurdos para justificar su actitud.

- Necesitan demostrar a su madre lo mal que han estado con su padre y lo malo que es este ("papá nos ha insultado").

En los casos expuestos se cumplen la mayoría de los síntomas que identifican en un/una menor alienado/a, como son: la campaña de denigración, justificaciones fútiles, ausencia de ambivalencia, fenómeno de independencia, ausencia de culpabilidad, generalización a la familia extensa etc. Asimismo podríamos estar ante un nivel severo en el que las visitas son imposibles y la hostilidad llega a un nivel extremo, pudiendo llegar incluso a la violencia física. Los síntomas anteriormente mencionados se presentan con total intensidad, pudiendo los menores quedar totalmente paralizados o mostrando un continuo y abierto comportamiento oposicionista y destructivo.

Respecto a los progenitores alienantes, con independencia de que sean en un caso la madre y en otro el padre, ambos coinciden en las características comunes de considerarse padres perfectos. Utilizan mecanismos de negación del SAP, estimando además que el fin justifica los medios; son creativos en las maniobras de exclusión que utilizan, son al mismo tiempo ingenuos. Son sobreprotectores de los/as hijos/as antes y después de la separación. Presentan una identificación patológica con los/as niños/as En casos extremos pueden desarrollar una relación simbiótica con el niño o la niña y rasgos paranoides, pueden ver alrededor de ellos solo maldad y malevolencia, especialmente proveniente del progenitor odiado.

El Plan de Intervención en Punto de Encuentro Familiar se dirige al tiempo de las visitas, a orientar tanto a los menores (en el apoyo a reducir la ansiedad y motivación a la relación con el progenitor rechazado), como a las familias, tanto al progenitor rechazado como al aceptado. Una cuidadosa evaluación del grado del SAP es fundamental para orientar la intervención, así como valorar el papel que juegan la familia extensa y el sistema judicial, en especial los letrados de las partes. Según la opinión de diferentes expertos, y coincidimos desde nuestra experiencia en el Punto de Encuentro Familiar de Sevilla, es difícil salir del SAP a través del mero cumplimiento de unos encuentros ordenados judicialmente, el SAP es una situación compleja que requiere intervenciones complejas y coordinadas desde diferentes instancias.

\section{CONCLUSIONES:}

No garantizar y obstaculizar el derecho fundamental del menor de mantener sus afectos y vínculos emocionales con sus progenitores y familiares, es una forma de maltrato que le provoca un daño a su bienestar y desarrollo emocional. Existen diferentes niveles en el Síndrome de Alienación Parental que está equiparado a una situación de riesgo, por lo que desde el ámbito profesional habrá que tomar las medidas de protección del/la menor destinadas a evitar tales situaciones.

No es fácil que solo bajo la presión que supone una orden judicial pueda solucionarse la situación que ha desencadenado un SAP. Si de verdad queremos solucionar este maltrato a los niños y niñas debemos abordarlo desde una intervención terapéutica, y no únicamente desde forzar un sistema judicial de visitas. 


\section{AGRADECIMIENTO:}

A Mayka Asenjo, Ma José Durán, Marian Gallardo y demás compañeras de Punto de Encuentro Familiar. A Sandra Millán por su colaboración.

\section{BIBLIOGRAFÍA:}

I. Rodríguez-Sacristán J: El hecho sorprendente del enfermar en la infancia. En: Psicopatología del niño y del Adolescente. Universidad de Sevilla, Secretariado de Publicaciones 1995. pp 29-44.

2. Hodges W: Interventions for children of divorce. $2^{a}$ ed. Editorial Bouder. Colorado, I99I.

3. Castells P: Separación y divorcio. Efectos psicológicos en los hijos. Como prevenirlos y curarlos. Editorial Cedecs. Barcelona, 1993.

4. Fagan P, Rector, R. The effects of divorce on America. The Heritage foundation, 1973, 2000.

5. Hill P: Recent advances in selected aspects of adolescent development. Journal of Child Psychology and Psychiatry 1993; 34: 69-99. 6. Seijo D, Fariña F, Novo M: Repercusiones del proceso de separación y divorcio. Recomendaciones programáticas para la intervención con menores y progenitores desde el ámbito escolar y la administración de justicia. Publicaciones 2002; 32: 199-218.

7. Fariña F, Arce R, Seijo D, Real S, Novo M: Guía Informativa. Ruptura de parella, non de familia. Editado por Consellería de Xustiza, Interior e Relacions. Santiago de Compostela, 2001.

8. Anuario Estadístico de Andalucía 2006. Instituto Estadístico de Andalucía.

9. Sepúlveda $G^{\text {a }}$ de la Torre MA. Experiencia en Punto de Encuentro Familiar. En: Los derechos de los niños y los procedimientos civiles. Centro de Estudios Jurídicos, 2006 (en prensa).
10. Turkat I D: Mediation and Parental Alienation Symdrome considerations for an intervention model. Family and Conciliation Courts Review.1999. 4 (3,7): 487-503.

II. Aguilar JM: Síndrome de Alienación Parental. Hijos manipulados por un cónyuge para odiar al otro. Editorial Almuzara. Córdoba 2004.

12. Gardner R: Recent trends en divorce and custody litigation. Academy Forum. 1985:29(2) :3-7.

13. Child alienation: Brainwashing children against fathers". http://childalienation.com.

14. Bolaños I: Hijos Alienados y Padres Alienados. Asesoramiento e Intervención en las Rupturas Conflictivas. I Congreso de Psicología Jurídica en Red (2004).

15. Junta de Castilla y León. Guía de Intervención en los Puntos de Encuentro de Castilla y León. VA-533-2006.

16. Bolaños I. 2000 Estudio descriptivo del Síndrome de Alienación Parental. En: Junta de Castilla y León. Guía de Intervención en los Puntos de Encuentro de Castilla y León. VA-533-2006.

17. Gardner R: Parental Alienation Syndrome vs Parental Alienation. Which Diagnosis Should Evaluators Use in Child-Custody Disputes?. The American Journal of Family Therapy. 2002. 30(2):93-II5.

18. Major J. Parents who have successfully fougt parental alienation syndrome. 2000. http://www.livingmedia.com/pas.htm. 